\title{
GESTÃO BASEADA EM VALOR APLICADA AO TERCEIRO SETOR ${ }^{* *}$
}

\section{VALUE BASED MANAGEMENT APPLIED TO THE TERTIARY SECTOR}

\author{
ALEXANDRE ASSAF NETO \\ Professor Titular do Departamento de Contabilidade \\ da Faculdade de Economia, Administração e Contabilidade \\ da Universidade de São Paulo - Campus Ribeirão Preto \\ E-mail: assaf@terra.com.br \\ ADRIANA MARIA PROCÓPIO DE ARAÚJO \\ Professora Associada do Departamento de Contabilidade \\ da Faculdade de Economia, Administração e Contabilidade \\ da Universidade de São Paulo - Campus Ribeirão Preto \\ E-mail: amprocop@usp.br \\ MARIANA SIMÕES FERRAZ DO AMARAL FREGONES \\ Professora Assistente do Departamento de Contabilidade \\ da Faculdade de Economia, Administração e Contabilidade \\ da Universidade de São Paulo - Campus Ribeirão Preto \\ E-mail:mafregonesi@usp.br
}

\section{RESUMO}

Nos últimos anos, o mundo assistiu ao crescimento do assistencialismo e das preocupações sociais. Pessoas se reúnem e formam instituições cujo único objetivo é tentar amenizar problemas sociais. Surge o chamado Terceiro Setor, que vem crescendo e conseguindo ajudar no suprimento das carências resultantes da incapacidade do governo em exercer o seu papel. No entanto, muitas organizações desse setor apresentam problemas de gestão. A metodologia centra-se em revisão bibliográfica sobre os temas principais do trabalho, além de uma pesquisa empírica. A pesquisa empírica mostrou que, na prática, é possível aplicar a GBV, sendo necessárias adaptações para a avaliação econômica da entidade. Este trabalho apresenta uma adequação da gestão baseada em valor, ferramenta sedimentada nas empresas lucrativas, para as empresas desse setor e apresenta o cálculo do EVA ${ }^{\bullet}$ para uma organização sem fins lucrativos.

Palavras-chave: Gestão Baseada em Valor; Terceiro Setor.

\section{ABSTRACT}

In recent years, the world has witnessed growing concern about social issues and assistance. People join to create organizations with the only goal of trying to mitigate social problems. This gives rise to the so-called Tertiary Sector, which is expanding and manages to help to fulfill the needs generated by the government's incapacity to play its role. Nevertheless, many organizations in this sector present management problems. The methodology focuses on a bibliographic review of the subject, as well as an empirical research. The empirical research has shown that it is actually possible to apply value based management, provided that modifications are made for the organization's economic assessment. This study presents an adaptation of value based management, a tool used by for-profit companies, to tertiary-sector organizations, as well as the calculation of $E V A^{\mathrm{TM}}$ for not-for-profit organizations.

Keywords: Value Based Management; Nonprofit Sector. 


\section{INTRODUÇÃO}

Muitas mudanças ocorreram no mundo empresarial nas duas últimas décadas. A grande competitividade obriga as empresas a se diferenciarem, a criarem vantagem competitiva. Isso associado à concentração de recursos em poucos grupos sociais gera dificuldade em atrair investimentos. Esse desafio eleva a importância das informações contábeis nas atividades gerenciais.

O advento da tecnologia da informação acabou transformando o conhecimento em um dos ativos mais importantes da organização. No entanto, a contabilidade não conseguia mensurar esse ativo intangível para ajustar o valor do patrimônio das empresas. Apesar de uma grande evolução nesse sentido, até os dias atuais, esse é um dos maiores desafios para os profissionais e acadêmicos dessa área.

Uma das teorias desenvolvidas nesse contexto foi a de Gestão Baseada em Valor. Mais do que calcular o lucro, muitas vezes enviesado pelas normas contábeis, era preciso mensurar a riqueza do acionista e mostrá-la aos proprietários de capital. Assim, em substituição às medidas tradicionais de desempenho, surge o conceito de valor econômico agregado aos acionistas. E esses passam a ser a figura central da empresa.

O objetivo principal de todas as empresas deve ser a maximização dos lucros dos detentores de capital, isto é, remunerar os donos do dinheiro. É a medida de desempenho financeiro que vê mais de perto, do que qualquer outro instrumento, o lucro econômico verdadeiro de uma empresa. (OLIVEIRA et al., 2002: 184)

Se por um lado, no contexto social atual, o foco de muitas empresas é aumentar a riqueza do acionista, por outro, o foco de muitas outras é aumentar a riqueza da sociedade. Explica-se: como conseqüência do crescimento da valorização do investidor e, muitas vezes, a qualquer custo, emerge a preocupação com as causas sociais e as relacionadas ao meio ambiente. Hart e Milstein (2004) defendem a criação de valor sustentável, no sentido de conciliar a valorização para o acionista e o desenvolvimento sustentável.

Com a queda do comunismo na última década, o capitalismo emergiu como a ideologia econômica dominante no mundo. Infelizmente, os resultados produzidos em dez anos de capitalismo global não têm sido uniformemente positivos. A saturação dos mercados desenvolvidos, a ampliação do fosso entre ricos e pobres, o crescimento dos níveis de degradação ambiental e a preocupação de que o mundo desenvolvido possa estar perdendo o controle sobre sua própria densidade populacional, vêm se combinando e criando entraves à economia global. (HART e MILSTEIN, 2004: 65)

Surgem, então, diversas organizações cujo único objetivo é defender tais causas, instituições em que não existe a figura do acionista. O crescimento das organizações não governamentais, aliado à preocupação com o meio ambiente e com as desigualdades sociais, levou a causa à mídia, mobilizando um grande número de adeptos.

As empresas começaram a perceber que o investimento em projetos não lucrativos poderia melhorar a sua imagem no mercado, adicionando valor ao acionista. Fischer et al. (2003: 5) analisam as alianças entre as empresas lucrativas $e$ as do chamado Terceiro Setor e afirmam que

o engajamento empresarial com causas comunitá-

rias e sociais não pode ser visto simplesmente como altruísmo, ele também pode ser importante para a estratégia da empresa.

O Terceiro Setor é constituído de organizações sem fins lucrativos e com um objetivo social bem definido, ou seja, firmas cuja finalidade maior é promover benefícios à sociedade. Geralmente, elas dependem de recursos oriundos de doações, transferência de fundos sem ônus e de trabalho voluntário.

Suas atividades são tipicamente públicas, apesar de serem pessoas jurídicas de direito privado. Ocorre que o Estado não consegue desempenhar seu papel social de maneira satisfatória. Daí, a sociedade se organiza em associações e fundações, buscando, ao menos, amenizar a inoperância do Estado. Muito ainda precisa ser feito, mas a sociedade organizada tem desempenhado um papel da mais alta importância social (CONSELHO FEDERAL DE CONTABILIDADE, 2003:37).

Sendo assim, as alianças com as empresas lucrativas são extremamente valiosas para as organizações sem fins lucrativos, pois, além de levarem recursos financeiros para essas entidades, disseminaram ainda mais, no Brasil, a cultura de preocupar-se com os problemas sociais do país. Atualmente, muitas escolas já ensinam às crianças a importância de proteger o meio ambiente e incentivam o voluntariado na ajuda ao próximo.

No entanto, muitas das empresas do Terceiro Setor surgiram por iniciativa de pessoas sem experiência em gestão e apresentam muitas dificuldades na sua administração. A instituição sem fins lucrativos não implica em empresa não lucrativa, tal expressão diz respeito à distribuição dos resultados. Todo lucro gerado deve ser reinvestido, não existe distribuição de dividendos (MELO et al., 2003), ou seja, não é verdade que essas organizações não podem ser lucrativas, elas podem e devem ser lucrativas, gerando recursos para investir em novos projetos sociais.

A escassez de recursos nessas empresas, visto que a maior parte delas depende da solidariedade alheia, exige, ainda mais, uma gestão eficiente da organização. O objetivo maior dessas organizações deve ser maximizar os benefícios gerados com cada real arrecadado. Logo, o lucro indica o uso eficiente dos recursos, ou seja, foi possível repor os gastos e ainda existe recursos para reinvestimento. O superávit no final do exercício, além de não ser ilegal, 
como se imagina, permite a ampliação da ajuda dada à sociedade pela organização.

Mas, na prática, essa gestão eficiente raramente acontece. TEXEIRA (2004:7) aponta a deficiência na gestão como um dos fatores de restrição a um maior desenvolvimento do Terceiro Setor:

As deficiências na gestão organizacional destas entidades, a pressão para buscarem sua auto-sustentação financeira, a escassez de apoio técnico e a grande diversidade de membros que compõe suas estruturas são restrições a um maior desenvolvimento do terceiro setor. Para reverter tal estado de coisas, uma grande parte de estudiosos do tema alerta para a necessidade de profissionalizar a gestão dessas instituições, ponto em que os conhecimentos e os princípios da Ciência da Administração podem dar uma significativa contribuição para o desenvolvimento do setor social.

Daí a importância de estudar melhor esse setor e de adequar as teorias das ciências administrativas a ele. Uma das dificuldades dessas organizações está na avaliação de desempenho. Fischer et al. (2003) apontaram a falta de indicadores de desempenho como um dos problemas encontrados nas alianças intersetoriais envolvendo o Terceiro Setor.

Enquadra-se aqui a finalidade deste trabalho. Dada a necessidade de aprimoramento de gestão nas empresas sem fins lucrativos, associada à necessidade de avaliar seu desempenho para alavancar recursos, torna-se preciso encontrar uma ferramenta de gestão capaz de melhorar o desempenho dessas organizações e ainda mostrar isso para os investidores. Daí, questiona-se: seria possível utilizar a gestão baseada em valor para suprir tal carência? Usar o valor econômico agregado, mas dessa vez não ao acionista, mas à comunidade? Sendo a causa das empresas não lucrativas empenharem-se para beneficiar a comunidade, seria possível afirmar que o seu objetivo é maximizar o valor econômico para a comunidade?

Com isso, o objetivo específico deste trabalho é verificar a aplicabilidade da gestão baseada em valor nas organizações do Terceiro Setor. Para tanto, serão discutidos, inicialmente, o conceito de Gestão Baseada em Valor e algumas pesquisas desenvolvidas para o Terceiro Setor. Posteriormente, será estudada a possibilidade de aplicação desse conceito às empresas sem fins lucrativos e, por fim, será visto um caso de mensuração do valor econômico agregado a uma fundação de tratamento de pessoas com câncer.

O trabalhado científico, em geral, demanda um método de análise. De acordo com Marconi e Lakatos (2002), entende-se por método o conjunto das atividades sistemáticas que permite alcançar um objetivo, traçando caminhos, detectando erros e auxiliando as decisões.

Para a elaboração do estudo, como metodologia, foi utilizada pesquisa empírica com um exemplo de caso, por meio de dados e informações da instituição. A primeira parte do estudo descreve a instituição que será usada como objeto de pesquisa e a segunda parte apresenta a aplicação da GBV em uma entidade filantrópica e as adaptações sugeridas. Os dados foram coletados por meio de pesquisa documental nas seguintes fontes primárias: relatórios contábeis publicados pela entidade, arquivos particulares com acesso permitido pela organização e tabela de pagamentos do Sistema Único de Saúde (SUS), disponível em < http:// portal.saude.gov.br/saude/> e da Associação Médica Brasileira (AMB), disponível em < http://www.amb.org.br/>.

$A$ pesquisa enquadra-se como qualitativa, ou seja, nesse tipo de pesquisa, o objeto de estudo não é reduzido à variável única, mas é estudado em sua complexidade e totalidade, em seu contexto diário. A pesquisa qualitativa vai ao encontro do objetivo deste estudo, pois se caracteriza por estudar práticas e interações sociais (FLICK, 2004).

\section{GESTÃO BASEADA EM VALOR}

O conceito de Value Based Management (VBM) conforme definido por Copeland; Koller; Murrin (2000:87):

A VBM é um processo integrador, cujo objetivo é melhorar o processo de tomada de decisões estratégicas e operacionais na organização como um todo, a partir da ênfase atribuída aos principais value drivers da empresa. A prioridade da VBM não deve ser a metodologia, mas sim a mudança na cultura da empresa. Um administrador que tenha o valor como princípio está tão interessado nas sutilezas do comportamento organizacional como em usar a avaliação como métrica do desempenho e ferramenta de decisão.

A Gestão Baseada em Valor defende que o maior objetivo de uma empresa é maximizar valor para o acionista, ou seja, aumentar, o máximo possível, o valor econômico agregado ao investidor. Para tanto, as receitas devem superar todos os gastos da empresa (custos e despesas), inclusive o custo de oportunidade do capital. Criar valor para uma empresa ultrapassa o objetivo de cobrir os custos explícitos identificados nas vendas. Incorpora o entendimento e o cálculo da remuneração dos custos implícitos (custo de oportunidade do capital investido), não cotejado pela contabilidade tradicional na apuração das demonstrações de resultados, e, conseqüentemente, na quantificação da riqueza dos acionistas.

O conceito de custo de oportunidade relaciona-se com a melhor alternativa de investimento rejeitada, sujeita a um nível de risco semelhante, ou seja, "custos associados com as oportunidades que serão deixadas de lado, caso a empresa não empregue seus recursos em sua utilização de maior valor" (PINDYCK e RUBINFELD, 1994: 257). Portanto, o empreendimento deve representar a melhor opção de aplicação de recursos. 
Para atingir tal objetivo, o negócio tem que aproveitar todas as oportunidades que agreguem mais valor econômico que a sua atividade operacional, na tentativa de atrair o investidor para si. Daí a importância da Gestão Baseada em Valor. É muito mais que cobrir os custos, é preciso identificar e aproveitar as oportunidades do ambiente externo à organização, além de criar projetos geradores de riqueza.

Para tanto, tal sistema indica o uso de estratégias financeiras e capacidades diferenciadoras que adicionem valor econômico. E ainda, a seleção de direcionadores de valor que irão mensurar o desempenho da empresa no alcance dos objetivos traçados para cada estratégia e para cada capacidade (Figura I).

Copeland; Koller; Murrin (2000) definem direcionadores de valor como elementos que têm mais impacto no valor da empresa. E afirmam que a seleção desses direcionadores pode beneficiar a empresa de três maneiras: ajudar os gestores e colaboradores a entender como o valor é criado e como pode ser maximizado; orientar para a melhor forma de alocação de recursos visando maximizar valor e unir todos os membros da unidade de negócios em torno das mesmas prioridades.

Funciona da seguinte forma: a empresa define estratégias de diferenciação, que irão agregar vantagem competitiva ao negócio, e estratégias financeiras, para criar valor para o acionista. Então, para cada estratégia serão definidos objetivos e para cada objetivo direcionadores de valor capazes de conduzir a empresa à geração de riqueza.

As estratégias definidas devem ser combinadas com as decisões operacionais, decisões de investimento e decisões de financiamento dos gestores. Rappaport (2001:98) defende a necessidade de analisar a atratividade do mercado de atuação do negócio. E ainda, que as estratégias relacionadas aos clientes estão diretamente relacionadas às estratégias financeiras.

Sem criar valor para o consumidor, não pode haver valor para o acionista. (...) Há custos associados com criar valor para o consumidor. O valor para o acionista somente irá materializar-se se os clientes estiverem dispostos a pagar estes custos.

Um dos direcionadores de valor mais usados é o $E V A^{\circledR 1}$ (Economic Value Added). Ele é conceituado como uma me- dida de desempenho econômico. É conhecido pela sigla $E V A^{\circledR}$. Foi desenvolvida por economistas e surgiu há mais de duzentos anos, com o objetivo inicial de medida de desempenho e sistema de gestão. (...) Na ênfase atual, $E V A^{\circledR}$ é a estrutura para um sistema completo de gerência financeira e remuneração variável que pode auxiliar o processo de tomada de decisões das empresas.

$\mathrm{Na}$ concepção do valor econômico, como o objetivo enunciado de qualquer empresa é gerar, em suas decisões financeiras, um retorno que remunere as expectativas de rendimentos de seus proprietários de capital, a comparação do Retorno sobre o Investimento (ROI) com o Custo Médio Ponderado do Capital (CMPC) permite identificar se a empresa está agregando ou destruindo valor econômico.

Uma das formas de calcular o $E V A^{\circledR}$ é: $E V A^{\circledR}=(\mathrm{ROI}$ - CMPC) x INV, em que: ROl é o índice de retorno sobre o investimento calculado pela divisão do lucro operacional pelo investimento (INV); CMPC é o custo médio ponderado de capital, que como o nome já diz é a média ponderada do custo de capital próprio e do capital de terceiros e INV é o investimento de capital no empreendimento, dado pelo total do ativo reduzido do passivo de funcionamento (passivo não oneroso).

Isso vale dizer que o valor econômico agregado é influenciado por qualquer fato que afete o lucro operacional (exemplos: variação da margem de lucro, mudanças na remuneração dos empregados, ocorrência de custos de estocagem, inadimplência de clientes etc.), o custo de capital (variação nas taxas de desconto ou custos de oportunidade, variação na estrutura de capital) ou no tamanho do investimento (tanto de capital próprio quanto de terceiros).

Não obstante, o EVA ${ }^{\circledR}$ representa o valor econômico agregado apenas do período (passado ou projetado) de ocorrência do lucro operacional. Para encontrar o valor adicionado da empresa, $M V A^{\circledR 2}$, é preciso aplicar o conceito de perpetuidade ao $E V A^{\circledR}$, descontando-o pelo custo de capital:

$$
\mathrm{MVA}^{\circledR}=\mathrm{EVA}^{\circledR} / \mathrm{CMPC} .
$$

Esse índice representa o valor da empresa deduzido do montante necessário para repor todos os seus ativos. Aqui se reflete o valor futuro da empresa, ou ainda, uma expectativa do mercado para os retornos a serem ofere-

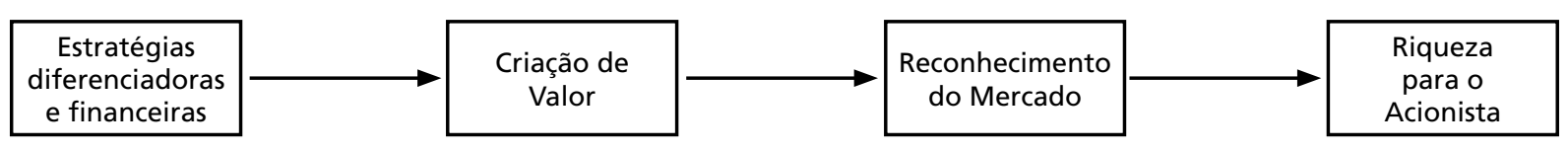

Fonte: ASSAF, 2003, p.169 (adaptado).

Figura 1

Visão Sintética de uma Gestão Baseada em Valor

\footnotetext{
I Marca registrada de propriedade da Stern \& Stewart. 2 Idem.
} 
cidos por ela, conceito amparado pelo princípio contábil da continuidade, ou seja, pressupõe-se que o empreendimento estará em funcionamento nos próximos exercícios. $M V A^{\circledR}$ é equivalente à estimativa do mercado de capitais do valor presente líquido ou NPV (método do fluxo de caixa descontado para avaliação de investimentos) de uma empresa.

No entanto, esses valores não podem ser calculados com os números diretamente extraídos da contabilidade tradicional. São necessários ajustes para não haver distorção do valor econômico agregado. Dois ajustes são comuns a qualquer empresa. O primeiro consiste em excluir as despesas financeiras do cálculo do lucro operacional. Isso se justifica porque a despesa financeira é decorrente de decisões de financiamento e o objetivo é encontrar o resultado advindo das decisões de investimento dos gestores. O segundo ajuste pede que o lucro operacional já esteja deduzido do imposto de renda, ou seja, tal tributo deve ser calculado sobre o resultado total das operações. Como conseqüência disso, mais uma correção se faz necessária: as despesas financeiras devem ser reduzidas pelo benefício fiscal concedido a elas.

Seu cálculo [do $\mathrm{EVA}^{\circledR}$ ] exige algumas adaptações nos demonstrativos de resultados, procurando, entre outras medidas, evidenciar sua parte operacional legítima, a segmentação do Imposto de Renda sobre os re- sultados da atividade e os benefícios fiscais provenientes do uso de capital de terceiros (ASSAF, 2003: 174).

É possível calcular o valor agregado para cada decisão de investimento ou financiamento da empresa. Outros autores (como MARTIN e PETTY, 2004; RAPPAPORT, 200I) colocam como fator crítico de sucesso na implantação de um sistema de gestão baseado em valor a vinculação do desempenho apresentado com o sistema de recompensas da empresa. Para que haja envolvimento com a criação de valor, a empresa deve desenvolver incentivos associados aos direcionadores de valor das atividades exercidas para cada cargo ou função na empresa.

A gestão baseada em valor muda a perspectiva de avaliação do desempenho dos negócios. O acionista passa a ser figura principal da gestão. No entanto, já existe pesquisa (HART e MILSTEIN, 2004) discutindo a questão do valor sustentável, ou seja, a criação de valor aliada ao crescimento sustentável. Esses autores, especificamente, mostram que adicionar valor a empregados, meio ambiente e projetos sociais acabam levando o valor agregado para o acionista. Mas ainda ficam algumas questões: é possível fazer VBM sem o foco no acionista? É possível que se estabeleça outra figura principal para a gestão, a sociedade, por exemplo, ainda usando tal ferramenta? Ainda há muita matéria para pesquisa nesse assunto.

\section{TERCEIRO SETOR}

Foram discutidos, na introdução deste artigo, o crescimento da participação do Terceiro Setor nas atividades empresariais brasileiras, o problema criado pela inexperiência em gestão, e o interesse das entidades lucrativas em financiar projetos desse setor. No entanto, ainda não foi aprofundado o conceito de Terceiro Setor.

$\mathrm{Na}$ verdade, existe um grande problema na definição de um conceito para Terceiro Setor. Devido aos incentivos fiscais, muitas empresas assumem a estrutura e a denominação legal de fundação, sem, de fato, possuírem as intenções de uma entidade sem fins lucrativos. Fischer $e$ Falconer (1998), também, discutem a dificuldade de consenso quanto a essa definição, inclusive devido a esse problema.

A definição de Fernandes (1 997:27) para Terceiro Setor:

é composto de organizações sem fins lucrativos,

criadas e mantidas principalmente pela participação voluntária, em um âmbito não governamental, dando continuidade às práticas tradicionais da caridade, da filantropia e do mecenato e expandindo o seu sentido para outros domínios, graças, sobretudo, à incorporação do conceito de cidadania e de suas múltiplas manifestações na sociedade civil.

Hudson (1999, apud COSTA e ROSA, 2003) define esse setor como um conjunto de atividades privadas com fins públicos e sem fins lucrativos, composto por institui- ções civis de qualquer origem - religiosa, comunitária, de trabalhadores, institutos e fundações empresariais e organizações não-governamentais e outras - diferenciando-se da lógica estrita de governo (público com fins públicos) e de mercado (privado com fins privados).

Salomon e Anheier (1992, apud MELO et al., 2003) consideram a necessidade de realizar comparações internacionais entre organizações dessa natureza e propõem uma definição mais ampla. Eles selecionaram cinco características comuns às organizações em estudo: (a) formalidade, mas não no sentido de legalidade e, sim, reuniões regulares, regras, ou algum nível de organização; (b) natureza privada, não pertencente ao governo, nem dirigida por ele; (c) não distribuir lucros, esses, se houver, devem ser investidos na missão da organização; (d) autonomia, não devem ser controladas por entidades externas; (e) voluntariedade, devem envolver algum grau de participação voluntária.

Com isso, ainda que não seja possível o consenso absoluto nas definições, percebe-se que mais do que na regulamentação, o Terceiro Setor está na intenção das organizações. Costa e Rosa (2003: 2) justificam afirmando que o nascimento do Terceiro Setor é avaliado por muitos com otimismo, pois são essas organizações sem fins lucrativos a via eficaz para assegurar a participação social, eliminar a ineficiência da burocracia estatal e assegurar a eficácia dos serviços públicos. 
Existem cerca de duzentos e cinqüenta mil Organizações da Sociedade Civil (OSCs) no Brasil, empregando, aproximadamente, um milhão e meio de pessoas e estão em diversas áreas de atividade: assistência social, educação, saúde, esportes e lazer, meio ambiente, geração de emprego e renda, artes e cultura, ciência e tecnologia, comunicação, segurança pública etc. Os tipos mais recentes de OSCs são as ONGs (Organizações não Governamentais), que se multiplicaram nos anos 80 , na defesa dos direitos humanos e em projetos de desenvolvimento social. As maiores delas são as da educação e da saúde, ressaltando novamente a discussão sobre os limites entre as que são mesmo sem fins lucrativos e as que já se confundem com empresas lucrativas (<www.rits.com.br $>$ ).

Na maior parte dos casos essas empresas atuam nos "pontos fracos" do governo, ou seja, elas vêm cobrir as falhas dos serviços oferecidos pelo governo.

O Terceiro setor vem atuar como uma extensão da ação do Estado tradicional, e amplia o espaço do próprio Estado, cobrindo lacunas de participação social (COSTA e ROSA, 2003:2).

No entanto, apesar de terem características peculiares, são empresas privadas, que devem ser administradas de modo a se sustentarem, e estão sujeitas a todas as intempestividades do ambiente no qual estão inseridas.

Afinal, as organizações do terceiro setor não são ilhas, separadas das demais dimensões da vida social; ao contrário, estão intimamente relacionadas com estas, sofrendo todos os tipos de influências e pressões do ambiente externo (TEIXEIRA, 2004: 5).

Esse autor reforça que as organizações do Terceiro Setor, além de estarem expostas aos problemas comuns das organizações com finalidades lucrativas, ainda estão sujeitas aos problemas "inerentes aos seus modos peculiares e distintos de ação" (IDEM), entre eles a desconfiança da sociedade quanto às suas intenções sociais.

Nesse contexto, a gestão eficaz torna-se essencial. Faz-se necessária a profissionalização da administração dessas instituições. Até porque elas têm melhorado os índices sociais e não podem deixar de existir tendo recursos, no mínimo humanos, para continuar. Cabe ao meio acadêmico tentar melhorar essa situação desenvolvendo ou adaptando teorias de gestão para o Terceiro Setor.

Ainda é pequena a preocupação em adequar o estudo da gestão às singularidades próprias deste tipo de organização (TEIXEIRA, 2004: I I).

Teixeira (2004) coloca, ainda, a necessidade da realização de pesquisas de campo para que se conheça melhor as organizações do Terceiro Setor e seja possível a elaboração de estudos e teorias organizacionais que contemplem suas particularidades, ou seja, um modelo de gestão mais condizente com as características desse setor.

Franco et al. (2003) e Melo et al. (2003) realizaram pesquisas com organizações do setor e encontraram os principais problemas enfrentados por elas: obter recursos financeiros; conseguir doadores permanentes; adquirir mão-de-obra voluntária permanente; adquirir mão-de-obra especializada profissional; realizar convênios/parcerias com o Estado e o setor empresarial; superar dificuldades materiais e/ou de infra-estrutura; vencer dificuldades de gestão e dificuldades conjunturais/externas à organização.

Assim, conhecendo algumas ameaças desse ambiente e as características peculiares a ele, será analisada a aplicabilidade da Gestão Baseada em Valor em organizações do Terceiro Setor.

\section{APLICAC̣ÃO DA GESTÃO BASEADA EM VALOR NAS ORGANIZAÇÕES DO TERCEIRO SETOR}

Avaliadas algumas teorias existentes sobre Gestão Baseada em Valor e sobre Terceiro Setor, o objetivo, agora, é tentar responder às perguntas colocadas na introdução deste artigo quanto à aplicabilidade dessa ferramenta às empresas sem fins lucrativos inseridas nesse setor. Para atender tal objetivo, será realizada uma análise da questão sob dois enfoques: a compatibilidade da teoria com as organizações sem fins lucrativos e a viabilidade de calcular o valor adicionado.

\subsection{Compatibilidade da VBM com o Terceiro Setor}

Mais que buscar simplesmente a maximização do valor para o acionista, a VBM busca "melhorar o processo de tomada de decisões estratégicas e operacionais na organização como um todo". Além disso, a prioridade dessa forma de gestão deve estar na mudança da cultura da empresa. Conforme já citado, um administrador que tenha o valor como princípio está tão interessado nas sutilezas do comportamento organizacional como em usar a avaliação como métrica do desempenho e ferramenta de decisão (COPELAND; KOLLER; MURRIN, 2000, p.87).

Esse foco da Gestão Baseada em Valor, aliado à necessidade de aprimorar as técnicas de administração das empresas do Terceiro Setor, traz a primeira perspectiva quanto à compatibilidade analisada neste tópico. A melhoria do processo de tomada de decisões estratégicas, sem dúvida, contribui para uma gestão mais eficaz dos recursos da organização (recursos escassos conforme mostrado no item anterior). Além disso, o fato de essas empresas já apresentarem um objetivo comum, que pode ser definido por agregar valor à comunidade, facilita a implantação de mudanças possivelmente necessárias na cultura organizacional. Com isso, por essa primeira perspectiva, percebe-se que existe a 
compatibilidade questionada, ou seja, a VBM como ferramenta de gestão que visa "melhorar o processo de tomada de decisões estratégicas e operacionais" pode ser usada para melhorar o processo de tomada de decisões nas empresas do Terceiro Setor que carecem de melhor gestão.

Uma outra perspectiva diz respeito ao objetivo maior da empresa de maximizar o valor econômico agregado ao acionista. Nas organizações do Terceiro Setor não existe a figura do acionista. Os proprietários de capital que investem nessas firmas não possuem expectativa de retorno financeiro. Contudo, esperam que tal investimento seja revertido para uma comunidade. Assim, apesar de não haver o acionista, existe sim o objetivo de maximização de valor econômico agregado, mas à comunidade (considera-se comunidade um conjunto de pessoas com as mesmas características/problemas, por exemplo, comunidade de menores abandonados da cidade de São Paulo). Ou seja, o valor que deveria remunerar o capital aplicado nessa instituição deve ser investido na produção de benefícios a uma determinada comunidade. E considerando que quanto maiores os benefícios gerados (e divulgados), maiores os recursos atraídos para o projeto, deve-se buscar a maximização dos benefícios gerados com o capital empregado.

Vale lembrar que as empresas do Terceiro Setor, apesar de não possuírem finalidades lucrativas, devem apresentar resultados positivos permitindo o reinvestimento em projetos sociais. Não obstante, muitas pessoas possuem um certo preconceito quanto à geração de lucro por parte dessas empresas. Uma justificativa para isso, conforme já discutido, é a existência de fundações ditas sem fins lucrativos, mas que, na verdade, não possuem uma missão de cunho social (TEIXEIRA, 2004). Apesar disso, empresas que administram melhor os seus recursos, conseguindo, inclusive, investir no marketing da instituição, acabam atraindo mais doadores de capital por divulgar os benefícios gerados à comunidade (exemplo disso é o Projeto Criança Esperança, patrocinado pela Rede Globo de televisão). Isso confirma a necessidade de maximização de valor agregado dada uma quantidade restrita de capital investido.

Por fim, a última perspectiva a ser analisada neste tópico verifica o processo exposto na figura I do item 2 (Gestão Baseada em Valor) deste artigo. Ela mostra o processo de gestão sugerido pela VBM, que é perfeitamente aplicável às empresas do Terceiro Setor. Serão definidas estraté- gias de diferenciação (por exemplo, um hospital destinado a oferecer tratamento do câncer às pessoas carentes que oferece também tratamento odontológico aos pacientes) para agregar vantagem competitiva ao negócio, e estratégias financeiras (por exemplo, buscar parcerias no setor privado "com fins lucrativos" para financiar os novos projetos sociais) para criar valor à comunidade (não ao acionista como proposto na teoria). Serão definidos objetivos estratégicos e, para cada objetivo, direcionadores de valor visando à geração de riqueza (por exemplo, quantidade de recursos obtidos em parcerias com setor privado).

As diferenças no processo são o foco da criação de valor, comunidade ao invés de acionista, e o reconhecimento do valor gerado, que não se dá pelo mercado, mas pela sociedade (figura 2). $\mathbf{O}$ Ou seja, a instituição cria valor para a comunidade, a sociedade (entenda-se como o conjunto de comunidades, carentes ou não, para o exemplo citado anteriormente, seriam todos os menores da cidade de São Paulo) reconhece esse valor e cria riqueza, ou seja, doadores e voluntários dispostos a contribuir com a instituição. Fazendo uma analogia com a teoria proposta para as empresas lucrativas, se lá a riqueza representa o capital que o mercado está disposto a pagar pela aquisição da empresa, aqui, no Terceiro Setor, ela representa o capital (e o trabalho) que a sociedade está disposta a investir na instituição.

Quanto à utilidade das informações geradas pela VBM para as organizações do Terceiro Setor, deve-se considerar a ausência, na maior parte delas, de controles de gestão (TEIXEIRA, 2004). Assim, no mínimo a Gestão Baseada em Valor será uma forma de mensurar eficiência. Mas ela pode ser muito mais do que isso.

O uso dos direcionadores de valor pode auxiliar a empresa a evitar dispêndio dos recursos, que são muito escassos, com atividades que não agreguem valor à comunidade. Ou ainda, pode verificar se os esforços para captação de recursos estão trazendo resultados satisfatórios. Mais ainda, dada a dificuldade em captar recursos, as empresas que conseguirem mostrar sua eficiência, principalmente, através de projetos estruturados, aumentam suas possibilidades de atrair recursos das empresas empenhadas em atuar com responsabilidade social.

Pode-se concluir que existe compatibilidade da teoria proposta pela VBM e o Terceiro Setor. As duas maiores pre-

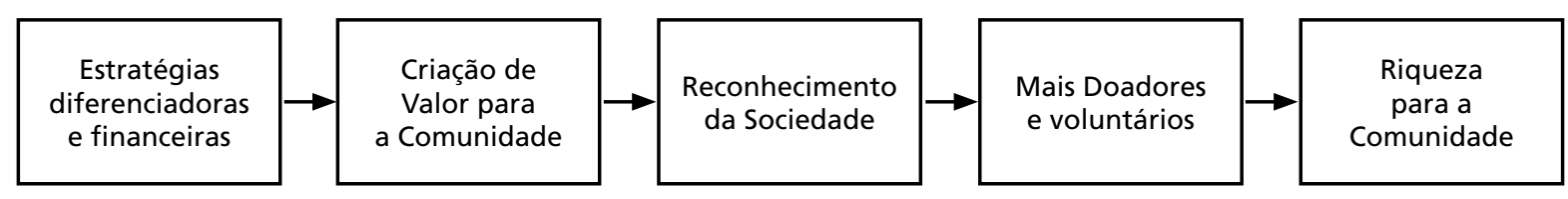

Fonte: ASSAF, 2003, p.169 (adaptado para o Terceiro Setor)

Figura 2

Visão Sintética de uma Gestão Baseada em Valor 
ocupações para analisar este tópico eram verificar a viabilidade de aplicar a teoria proposta de Gestão Baseada em Valor, desenvolvida para empresas lucrativas, em empresas sem fins lucrativos e a possibilidade de atender às necessidades das empresas desse setor, ou seja, melhorar seu processo de gestão. A resposta para a primeira preocupação foi mudar o foco no acionista para um foco na comunidade, o que continua condizente com a teoria proposta. A segunda preocupação foi resolvida pelos próprios Copeland; Koller e Murrin (2000) quando eles trazem a utilidade da VBM como ferramenta de melhoria na tomada de decisão, que é a maior necessidade das empresas desse setor. Assim, por esse enfoque é possível usar essa ferramenta de gestão nas organizações sem fins lucrativos.

\subsection{Possibilidade de Cálculo do Valor Adicionado}

Para analisar esse enfoque, foi selecionado o $\mathrm{EVA}^{\circledR}$ como indicador de desempenho quanto ao valor adicionado. A escolha foi baseada nas premissas:

a) entre os modelos mais estudados, esse parece atender com maior grau de eficiência à questão da relevância e confiabilidade da informação contábil;

b) o modelo está estruturado com informações objetivas;

c) cobertura dos princípios básicos de finanças, o da maximização da riqueza dos acionistas e o da apuração do valor da empresa, considerando o retorno futuro esperado pelos investidores, excluído o custo do capital.

De acordo com a fórmula proposta no item 2 (Gestão Baseada em Valor), para calcular o valor do $\mathrm{EVA}^{\circledR}$. é preciso conhecer três valores: ROI (Retorno sobre o Investimento), CMPC (Custo Médio Ponderado de Capital) e INV (valor total do Investimento excluindo-se o passivo não oneroso).

Para calcular o ROI, é preciso conhecer as receitas, custos, despesas e impostos da organização, além do investimento (INV). As empresas formalizadas como organizações sem fins lucrativos devem divulgar tais informações (Balanço Patrimonial e Demonstração de Superávit ou Déficit) para a sociedade, assim como as sociedades anônimas. Isso implica ser possível obter os valores para cálculo do $\mathrm{ROI}$ e do INV das instituições.

No entanto, a receita apresentada nas demonstrações refere-se, predominantemente, a valores recebidos em doação, que não podem ser diretamente relacionados com os custos dos serviços prestados (não existe relação de proporcionalidade entre eles), portanto, não é possível afirmar que a empresa que apresenta maior resultado é a que mais contribui para a comunidade. Por exemplo, imagine duas instituições que ajudaram a mesma quantidade de pessoas gastando o mesmo valor monetário para tal, mas uma arrecadou mais doações que a outra; não é possível afirmar que a instituição que arrecadou mais adicionou um maior valor à comunidade, apesar de apresentar um resultado maior.
Dessa forma, o EVA ${ }^{\circledR}$ não irá refletir o valor adicionado à comunidade. Isso acontece porque a receita apresentada na demonstração do resultado não é gerada pelo sacrifício exposto no custo dos serviços prestados. Logo, a sugestão é usar um valor de receita que seja compatível com esses custos, qual seja, adotar um valor de mercado para o serviço prestado. Explica-se: se a organização do Terceiro Setor é uma creche gratuita, a receita unitária seria a mensalidade cobrada se ela fosse uma creche paga.

Aqui surge um dilema: qual valor de mercado deverá ser usado? A princípio, três opções serão levantadas. Uma delas seria adotar um índice de preços com uma base padrão, ou seja, calcular regularmente a média de preços de uma "cesta de instituições", como acontece com o Índice de Preços ao Consumidor (IPC divulgado pela FIPE - Fundação Instituto de Pesquisas Econômicas da FEA/USP). De acordo com a metodologia da FIPE, o índice de inflação é calculado como uma média geométrica ponderada das variações de preços dos bens ofertados ao consumidor. Nesse caso, o valor de mercado ou de referência para as empresas do Terceiro Setor, seria a média dos preços praticados pelo Estado, pelos planos de saúde e pelos próprios médicos ("particulares") ponderados por sua participação no uso geral da população. Ou seja, o percentual da população total de pacientes que se trata pelo SUS (Sistema Único de Saúde do Estado) seria a ponderação para o preço que o governo paga pelo serviço aos profissionais da saúde no cálculo do valor referencial. O mesmo raciocínio vale para os outros modos de pagamento dos serviços da saúde.

A segunda opção seria utilizar os valores referenciais sugeridos pelos órgãos reguladores das classes de profissionais da saúde. Assim, para os serviços médicos seriam usados os valores referenciais oferecidos pela Associação Médica Brasileira (AMB), para os serviços de fisioterapia, os valores oferecidos pelo Conselho Regional de Fisioterapia e Terapia Ocupacional (CREFITO) etc.

Por fim, a terceira opção, que será adotada neste trabalho, é utilizar como base os valores que o governo paga pelos serviços prestados ao SUS. Esses valores estão dispostos em uma tabela com a discriminação do procedimento e o valor a ser pago por ele (disponível em <www. saude.gov.br $>$ ). A principal razão para a adoção dessa tabela como valores de mercado ou valores de referência é o fato de as organizações do Terceiro Setor atenderem pessoas carentes. Isto é, se os pacientes são pessoas que não podem pagar pelo serviço diretamente ou por um plano de saúde, eles seriam atendidos às custas do Estado, ou seja, estariam de fato sendo tratados pelo SUS. Além disso, vale lembrar que "o Terceiro setor vem atuar como uma extensão da ação do Estado tradicional" (COSTA e ROSA, 2003:2), ou seja, ele tenta cumprir os deveres de Estado que o governo não consegue cumprir.

A substituição da receita de doações pela receita incorrida caso a organização recebesse pelos serviços a valores referenciais do governo se justifica, no contexto de Gestão Baseada em Valor aplicada ao Terceiro Setor, por representar um valor revertido para a comunidade com a 
existência da instituição. Ou seja, como a organização está "cumprindo" um dever do Estado, deverá liberar recursos do orçamento público e o governo pode redirecionar tais recursos para outra necessidade básica, aumentando os benefícios gerados para a sociedade.

Com isso, calcula-se um ROI condizente com a realidade e com a teoria do valor econômico adicionado. Portanto, a questão a se discutir, agora, se refere ao CMPC (Custo Médio Ponderado de Capital). Para calcular essa taxa devem ser conhecidos a estrutura de capital da empresa, o custo do capital de terceiros e o custo de oportunidade do capital próprio. Quanto aos dois primeiros valores, não existe dificuldade em levantá-los dada a existência de contratos de empréstimos (quando houver capital de terceiros onerosos). Mas o custo de oportunidade do capital próprio gera discussão.

Em primeiro lugar é importante analisar a questão do "próprio" nesse caso. O patrimônio líquido das instituições sem fins lucrativos é chamado de patrimônio social e é composto por duas contas principais: Fundo Patrimonial e Superávit ou Déficit Acumulado. A primeira é equivalente ao capital social, mas representa os recursos obtidos por doações e investidos em ativo permanente (as doações usadas para manter a atividade da organização são consideradas receitas não operacionais). A segunda é equivalente a Lucros e Prejuízos acumulados, ou seja, acumula os resultados obtidos na operação da empresa (CONSELHO FEDERAL DE CONTABILIDADE, 2004).

Assim, o capital próprio é oriundo de doações ou resultado da própria operação. É possível afirmar que existe o custo de oportunidade do capital próprio, apesar de não haver distribuição de resultados, porque há necessidade de atrair investidores para a organização, ou seja, existe um custo de captação de recursos oferecidos em doação.

Sendo assim, a questão é como será calculada essa taxa. Baseado no conceito de custo de oportunidade, são propostas duas alternativas. A primeira é utilizar o custo do capital de terceiros, visto que, caso não haja doações, a empresa terá que recorrer a esse capital para sustentar suas operações. A segunda é usar o maior ROI das empre- sas "concorrentes" por esse tipo de investimento, ou seja, usar a melhor rentabilidade das organizações de Terceiro Setor que concorrem por doações. Nesse caso, também devem ser considerados os benefícios oferecidos ao doador de recursos, como o benefício fiscal, já que o imposto de renda permite a dedução do gasto apenas em casos e em instituições específicas.

Finalmente, apesar de algumas divergências quanto aos valores a serem utilizados, mostra-se possível o cálculo do valor adicionado nas empresas de Terceiro Setor. $A$ análise do caso prático de cálculo do valor adicionado à comunidade irá ilustrar melhor isso. Logo, sob esse enfoque, também, é possível aplicar a Gestão Baseada em Valor às empresas desse setor.

Vale lembrar que os enfoques analisados não esgotam as possíveis visões quanto à aplicação desse modelo. Mas mostram que, sob esses aspectos, verifica-se perfeitamente possível o uso dessa ferramenta em empresas sem fins lucrativos, trazendo, inclusive diversos benefícios para o desenvolvimento do Terceiro Setor.

Araújo (2003: 129-130) descreve dois "requisitos que todas as empresas devem atender para que seja implantado com sucesso, independentemente do seu porte", o uso do $E V A^{\circledR}$ como medida de desempenho. O primeiro é a existência de "um bom sistema contábil e de informações que reflita adequadamente a situação econômica e financeira da empresa", propiciando os dados necessários para o cálculo do $E V A^{\circledR}$. O segundo consiste em "um bom entendimento, pelos seus gestores, sócios e empregados, da estrutura conceitual do EVA ${ }^{\circledR}$ " e da Gestão Baseada em Valor.

Assim, uma limitação que pode ser colocada para a aplicação da VBM nas empresas do Terceiro Setor é a ausência de um bom sistema de informações. No entanto, isso não impede que se coloque um sistema primário para fins de aplicação dessa ferramenta e depois se aprimore tal sistema. As informações básicas necessárias são geradas porque certamente existe um controle contábil, o que não há são informações elaboradas.

\section{CÁLCULO DO VALOR ECONÔMICO AGREGADO À COMUNIDADE PELA FUNDAÇÃO SOBECCan}

O objeto de estudo, neste tópico, é uma fundação de direito privado sem fins lucrativos, originada em 1994 . com sede em Ribeirão Preto (SP). A Fundação SOBECCan (Sociedade Benemérita de Combate ao Câncer) é a mantenedora do Hospital do Câncer de Ribeirão Preto. Em 200I, foi classificada como a $215^{\text {a }}$ maior entidade beneficente do Brasil, de acordo com a análise efetuada pela Kanitz $\&$ Associados.

A missão da empresa é "promover o melhor à comunidade na luta contra o câncer" e está bem disseminada entre seus membros. A empresa possui 28 funcionários, incluindo autônomos, terceirizados e estagiários. Além dis- so, conta com um grupo voluntariado (GVAI) com mais de sessenta voluntários ativos nas atividades da fundação.

O hospital realiza, sempre que possível, parcerias com o setor privado (com fins lucrativos) para realização de seus projetos. Recentemente, teve um projeto seu escolhido em uma campanha da Avon, empresa de cosméticos, em prol do câncer de mama. O projeto, chamado "MamaMóvel", permitiu a prestação de mais um serviço à comunidade. É um ambulatório móvel que, quinzenalmente, vai aos bairros da periferia e atende às mulheres fazendo exames preventivos.

O hospital atende por convênios médicos com instituições privadas e gratuitamente àqueles que não podem 
pagar. São realizados quase 500 atendimentos por mês, sendo cerca de $70 \%$ deles a pacientes carentes que não pagam pelo tratamento. Além dos médicos oncologistas e do tratamento quimioterápico, são oferecidos aos pacientes serviços de odontologia, fisioterapia, musicoterapia, psicologia e serviço social. Para os casos mais graves, também é oferecido o tratamento na casa do doente (CSO - Clínica de Suporte Oncológico).

A receita da organização, atualmente, é oriunda dos convênios médicos e de doações e eventos. A primeira é a chamada receita operacional, já que é o preço pago pelo cliente pelos serviços recebidos, e é responsável por aproximadamente $40 \%$ da receita total (ver demonstrações de resultado em anexo). O restante é proveniente das receitas não operacionais, como: doações, jantares, bingos, renda do Bazar da Pechincha e outros eventos, sendo a maior parte dessa receita arrecadada pelo GVAI.

Assim, para cálculo do $E V A^{\circledR}$ dessa instituição, as receitas não operacionais deverão ser substituídas pelo valor de mercado de todos os serviços gratuitos prestados à comunidade. Conforme visto no item anterior será usado como valor de mercado a tabela de preços de procedimentos da saúde do SUS. A tabela 10 mostra o cálculo do valor da receita de serviços prestados gratuitamente à comunidade.

Para compor a tabela I, foram coletados dados com a Fundação e com o SUS. Os dados da Fundação foram coletados através de entrevista concedida pela contadora da instituição e análise dos documentos por ela fornecidos e os valores referenciais do SUS foram obtidos através de pesquisa documental. Vale ressaltar que a receita total obtida com essas informações não corresponde ao valor exato que o Estado pagaria pelos serviços prestados à comunidade. Devido à falta de informações precisas, os valores de Hormonioterapia, Quimioterapia, Biopsia e Odontologia são aproximações da realidade. Explica-se: existe uma grande variedade de serviços relacionados a esses conceitos (por exemplo, na tabela referencial do SUS existem mais de 120 tipos de tratamentos quimioterápicos com valores que variam de $R \$ 42,10$ a $R \$ 8.064,50)$ e eles não estão diferenciados nos controles internos da instituição; assim, foram usados como base os tipos de serviços mais freqüentes em cada categoria. O correto seria, à medida que o serviço fosse prestado, categorizá-lo pela tabela de referência (trabalho para o próximo artigo), assim a receita "fictícia" gerada seria um retrato fiel da realidade.

No entanto, como o objetivo deste tópico é ilustrar o modo de calcular o valor econômico agregado à comunidade, essas aproximações não inviabilizam o exemplo, pois o cálculo da receita de serviços gratuitos já foi bastante discutido.

Como a empresa não apresenta capital oneroso de terceiros, somente o passivo de funcionamento, não existe necessidade de ajustar o resultado operacional, pois não existe despesa financeira que represente custo de capital de terceiros. Assim, a tabela 20 mostra o cálculo do resultado operacional considerando a substituição das receitas de doações pela receita exposta na tabela I. Os demais valores permaneceram inalterados, por isso só são apresentadas as linhas com totais (a demonstração original completa encontra-se anexa).

A tabela 2 mostra, ainda, o cálculo do $\mathrm{EVA}^{\circledR}$ e do $\mathrm{EVA}^{\circledR}$ Ajustado. Para o cálculo de ambos, adotou-se como custo de capital (CMPC) a taxa Selic (taxa de juros livre de risco no Brasil), conforme discutido no item sobre a possibilidade de cálculo deste indicador para as empresas do Terceiro Setor.

$\mathrm{O} \mathrm{EVA}^{\circledR}$ apresenta um valor negativo aproximado de 280 mil reais. Isso significa que a Fundação está destruindo valor econômico, ou seja, seu resultado operacional não é capaz de remunerar o capital investido, mesmo que o governo remunerasse a instituição pelo serviço por ela prestado à comunidade. Um fator deve ser destacado: nas

Tabela 1 - Composição dos serviços gratuitos prestados à comunidade - 2003

\begin{tabular}{l|c|c|c} 
Serviços prestados & Atendimentos (unidades) & Valor pelo SUS (R\$) & Receita gerada (R\$) \\
Consulta & 1.805 & 7,55 & $13.627,75$ \\
\hline Hormonioterapia & 353 & 147,10 & $51.926,30$ \\
\hline Quimioterapia & 208 & $1.062,65$ & $221.031,20$ \\
\hline Coleta & 374 & 0,50 & 187,00 \\
\hline Hidratação & 10 & 0,51 & 5,10 \\
\hline Curativos & 69 & 0,51 & 35,19 \\
\hline Biopsia & 52 & 14,66 & 762,32 \\
\hline CSO & 32 & 16,63 & 532,16 \\
\hline Odontologia & 86 & 1,74 & 149,64 \\
\hline Psicologia & 92 & 2,55 & 234,60 \\
\hline Serviço Social & 77 & 2,28 & 175,56 \\
\hline Fisioterapia & 945 & 2,55 & $2.409,75$ \\
\hline TOTAL & 4.103 & & $291.076,57$
\end{tabular}


Tabela 2 - Cálculo do Resultado Operacional, do EVA ${ }^{\circledR}$ e do EVA ${ }^{\circledR}$ Ajustado

\begin{tabular}{|c|c|}
\hline \multicolumn{2}{|c|}{ Cálculo do Resultado Operacional no ano 2003 (em R\$) } \\
\hline & 2003 \\
\hline \multicolumn{2}{|l|}{ RECEITAS } \\
\hline Receitas Operacionais de Prest. Serviços: & 633.600 \\
\hline Convênios de Saúde Públicos & 156.452 \\
\hline Convênios de Saúde Privados & 186.071 \\
\hline Serviços Gratuitos Prestados à Comunidade & 291.077 \\
\hline Deduções das Receitas & $(2.084)$ \\
\hline Receitas Não Operacionais: & 3.291 \\
\hline Receita c/ Utilização da Marca & - \\
\hline Reversão de Despesas & 3.291 \\
\hline Receitas Financeiras: & 13.011 \\
\hline Total das Receitas & 647.818 \\
\hline \multicolumn{2}{|l|}{ DESPESAS } \\
\hline Custos dos Serviços Prestados & 374.975 \\
\hline Despesas Administrativas & 433.765 \\
\hline Despesas Não Operacionais & 30.261 \\
\hline Outras Despesas & 41.378 \\
\hline Total das Despesas & 880.379 \\
\hline Resultado Operacional & $(232.561)$ \\
\hline
\end{tabular}

\begin{tabular}{l|c}
\multicolumn{2}{c}{ CÁLCULO EVA $^{\oplus}$} \\
\hline ROI & $-80,90 \%$ \\
\hline Resultado Operacional & $(232.561)$ \\
\hline Investimento & 287.467 \\
\hline CMPC (Selic) $^{-} 16,50 \%$ \\
\hline EVA $^{\circledR}[=($ ROI-CMPC)xINV] & $(279.993)$ \\
\hline \multicolumn{2}{|c}{} \\
\hline CÁLCULO EVA $^{\oplus}$ AJUSTADO \\
\hline ROI Ajustado & $-31,64 \%$ \\
\hline Resultado Oper. Ajustado & $(90.952)$ \\
\hline Investimento & 287.467 \\
\hline CMPC (Selic) & $16,50 \%$ \\
\hline EVA ${ }^{\circledR}[=($ ROI-CMPC)xINV] & $(138.384)$
\end{tabular}

despesas administrativas da DRE do hospital existe uma despesa extraordinária no valor de R\$141.609 referente à perda de créditos a receber (decorrente de problemas administrativos com uma instituição para a qual prestava serviços). Isso se origina de um problema que vem de anos atrás, portanto, é de fato uma despesa administrativa normal da organização. Por isso, foi calculado um EVA ${ }^{\circledR}$ ajustado, ou seja, desconsiderando o valor dessa perda que distorcia muito o desempenho da empresa.

Ainda assim, o valor econômico agregado é negativo, mostrando que são necessárias mudanças na gestão da empresa. Deve-se considerar o fato de os valores referenciais do SUS serem ínfimos (é difícil aceitar que o governo pague cerca de dois dólares para uma consulta médica), mas se fosse um hospital público, deveria sobreviver com esse valor. Deve-se considerar, ainda, que as receitas não são reflexos fiéis da realidade, já que não foi possível, categorizar os diferentes tratamentos (uma mudança no tipo de quimioterapia, por exemplo, pode significar um acréscimo de até sete mil reais na receita).

Contudo, foi possível ilustrar que é possível calcular o valor econômico agregado de uma instituição sem fins lucrativos com foco voltado para a comunidade, como era o objetivo deste trabalho, considerando as ressalvas apresentadas durante o estudo.

\section{CONCLUSÕES}

Damodaran (<www.damodaran.com $>$ ) afirma que toda organização precisa de um objetivo e para as organizações sem fins lucrativos (non-for-profit), ele deve ser declarado em termos de serviços ou benefícios que se pretende proporcionar. E tais objetivos serão a base para decisões quanto à alocação de recursos e escolha entre alternativas.

Assim, além de possível, é necessária a implantação de um sistema de controle estratégico na organização. E a VBM faz esse papel perfeitamente, além de apoiar, também, as tomadas de decisões operacionais. A mudança de foco (do acionista para a comunidade) não inviabiliza a ferramenta, permitindo a adequação ao Terceiro Setor.

Talvez possa ser desenvolvido futuramente até um direcionador de valor agregado à comunidade melhor que o $\mathrm{EVA}^{\circledR}$, mas, ainda assim, é possível melhorar significativamente a gestão dessas empresas que contribuem tanto 
para a comunidade. No Brasil, um país com tantos problemas sociais, a melhoria no valor agregado à comunidade pelo Terceiro Setor chega a ser uma necessidade.

Este trabalho não esgotou as questões sobre esse as sunto, longe disso. Muitas questões ainda devem ser discutidas, por exemplo: como avaliar a eficiência da empresa em captar recursos? Os doadores (de trabalho ou capital) podem ser considerados um goodwill dessas organizações? Como o governo pode incentivar as empresas e as pessoas a contribuírem mais com esse setor (já que atualmente esse incentivo é muito restrito)? E muitas outras que se espera que este trabalho ajude a levantar.

Neste artigo, foram levantadas algumas questões $e$ mostrou-se a viabilidade do uso de uma ferramenta de gestão tão importante em um setor fundamental para 0 desenvolvimento econômico e social do país. O Terceiro Setor apresenta indícios de ser extremamente importante para que o Brasil tenha uma classificação e reconhecimento mais positivo perante a comunidade internacional.

\section{Referências Bibliográficas}

ARAÚJO, M.L. Utilização do EVA - Economic Value Added como Medida de Desempenho econômico e financeiro por empresas de Pequeno e Médio Porte: um estudo de caso. 2003. Dissertação (Mestrado). Faculdade de Economia, administração e Contabilidade, Universidade de São Paulo, São Paulo.

ASSAF NETO, A. Finanças Corporativas e Valor. São Paulo: Atlas, 2003.

CONSELHO FEDERAL DE CONTABILIDADE. Manual de procedimentos contábeis e prestação de contas das entidades de interesse social. Brasília: CFC, 2003. Disponível em <www.rits.org.br>. Acesso em 06/08/2004.

COPELAND, T.; KOLLER, T.; MURRIN, J.. Avaliação de Empresas - Valuation. Tradução: Maria C.S.R. Ratto. McKKinsey \& Company, Inc.. São Paulo: Makron Books, 2000.

COSTA, A.L.; ROSA, S.T. Análise comparativa da eficiência e eficácia de gestão entre organizações do terceiro setor e organizações governamentais: um estudo de casos múltiplos nos serviços de educação infantil. In: Encontro da Associação Nacional de Programas de Pós-graduação em Administração (EnANPAD), XXVII, Anais, 2003, Atibaia.

FERNANDES, R.C.. O que é o Terceiro Setor?. São Paulo: Paz e terra, 1997.

FISCHER, R. M.; BOSE, M.; MENDONÇA, L.R.; FEDATO, C.. Monitoramento de Projetos Sociais: um Desafio para as Alianças Intersetoriais. In: Encontro da Associação Nacional de Programas de Pós-graduação em Administração (EnANPAD), XXVII, Anais, Atibaia, 2003.

; FALCONER, Andrés Pablo. Desafios da parceira governo e Terceiro Setor. Revista de Administração. São Paulo: USP, v. 33, n. 1, p. 12-19, janeiro/março 1998.

FLICK, Uwe. Uma introdução à Pesquisa Qualitativa. 2a ed.. Porto Alegre: Bookman, 2004.

FRANCO, J.; PEREIRA, M.F.; SARTORI, R.. Captação de Recursos para o Terceiro Setor: um estudo na cidade de Maringá-PR. In: Encontro da Associação Nacional de Programas de Pós-graduação em Administração (EnANPAD), XXVII, Anais, Atibaia, 2003.

HART, S.L.; MILSTEIN, M. B.. Criando Valor Sustentável. RAE Executivo, São Paulo, v.3, n², p. 65-79, 2004. Texto traduzido por Pedro F. Bendassolli. Artigo originalmente publicado na Academy os Management Executive, v. 17, n. 2, p. 56-69, 2003.

MARCONI, M. A.; LAKATOS, E. M.. Técnicas de pesquisa: planejamento e execução de pesquisas, amostragens e técnicas de pesquisas elaboração, análise e interpretação de dados. $5^{\text {a }}$ ed.. São Paulo: Atlas, 2002.

MARTIN, J.D.; PETTY, J.N.. Gestão Baseada em Valor: a resposta das empresas à revolução dos acionistas. Tradução: José Guimarães Alcântara. Rio de Janeiro: Qualitymark, 2004.

MELO, V. P.; FISCHER, T.; SOARES Jr, J. S.. Diversidades e Confluências no Campo do Terceiro Setor: Um Estudo de Organizações Baianas. In: Encontro da Associação Nacional de Programas de Pós-graduação em Administração (EnANPAD), XXVII, Anais, Atibaia, 2003.

OLIVEIRA, L. M.; PEREZ Jr, J. H.; SILVA, C. A. S.. Controladoria Estratégica. São Paulo: Atlas, 2002.

PINDYCK, R. S.; RUBINFELD, D. L.. Microeconomia. Tradução: Pedro Catunda. São Paulo: Makron Books, 1994.

RAPPAPORT, A. Gerando valor para o Acionista: um guia para administradores e investidores. Tradução: Alexandre L. G. Alcântara. São Paulo: Atlas, 2001.

TEIXEIRA, R.F. Discutindo o terceiro setor sob o enfoque de concepções tradicionais e inovadoras de Administração. Caderno de Pesquisas em Administração. São Paulo: FEA-USP, v.11, no. 1, p. 1-15, 2004.

$<w w w . d a m o d a r a n . c o m>$. $\quad<w w w . s a u d e . g o v . b r>$. $\quad<w w w . s o b e c c a n . o r g . b r>$.

\section{NOTA - Endereço dos autores}

Universidade de São Paulo

Faculdade de Economia, Administração e Contabilidade

Departamento de Contabilidade
Av. Bandeirantes, 3.900

Ribeirão Preto - SP

14.040-900 
FUNDAÇÃO SOBECCan - PESOUISA, PREVENÇÃO E ASSISTÊNCIA DO CÂNCER

1) BALANÇOS PATRIMONIAIS EM 31 DE DEZEMBRO (Em reais R\$)

\begin{tabular}{|c|c|c|c|c|c|}
\hline ATIVO & 2003 & 2002 & PASSIVO & 2003 & 2002 \\
\hline CIRCULANTE & 171.185 & 340.949 & CIRCULANTE & 49.293 & 119.197 \\
\hline Caixa & 1.937 & 1.339 & Fornecedores & 12.978 & 45.462 \\
\hline Bancos C/ Movimento & 12.668 & 22.514 & Salários a Pagar & 7.848 & 9.841 \\
\hline Contas a Receber (nota 3) & 129.449 & 267.377 & INSS a Recolher & 14.200 & 4.705 \\
\hline Adiantamentos a Fornecedores & 82 & 665 & FGTS a Recolher & 1.251 & 1.372 \\
\hline Impostos a Recuperar & - & 796 & Encargos Municipais & 928 & 424 \\
\hline \multirow[t]{2}{*}{ Estoques (nota 2.2) } & 27.049 & 48.259 & IRRF a Recolher & 244 & 54 \\
\hline & & & PIS a Recolher & 182 & 210 \\
\hline PERMANENTE (nota 2.3) & 165.576 & 179.243 & Cheques a Compensar & - & 540 \\
\hline Equipamentos Hospitalares & 124.103 & 116.833 & Aluguel - Santa Casa & - & 36.398 \\
\hline Equip. e Componentes Informática & 37.825 & 35.604 & Contas a Pagar & 1.044 & - \\
\hline Móveis e Utensílios & 43.206 & 43.206 & Provisões de Férias e Encargos & 10.618 & 20.190 \\
\hline Veículos & 15.550 & 15.550 & & & \\
\hline Equipamentos de Escritório & 4.417 & 329 & PATRIMÔNIO SOCIAL & 287.467 & 400.995 \\
\hline Equipamentos Odontológicos & 8.765 & 6.765 & Patrimônio Social Estatutário & 89.692 & 80.422 \\
\hline Instalações & 17.156 & 17.156 & Fundo Patrimonial & 436.526 & 436.526 \\
\hline Benfeitorias em Propriedade de Terceiros & 20.336 & 13.805 & Reserva de Reavaliação & 44.630 & 44.630 \\
\hline Marcas e Patentes & 6.972 & 6.775 & Déficits Acumulados & $(283.381)$ & $(160.583)$ \\
\hline Direito de Uso de Software & 17.424 & 17.424 & & & \\
\hline Depreciações / Amortizações Acumuladas & $(130.178)$ & $(94.203)$ & & & \\
\hline TOTAL ATIVO & 336.761 & 520.192 & TOTAL PASSIVO & 336.761 & 520.192 \\
\hline
\end{tabular}

FUNDAÇÃO SOBECCan - PESOUISA, PREVENÇÃO E ASSISTÊNCIA DO CÂNCER

2) DEMONSTRAÇÕES DO SUPERÁVIT OU DÉFICIT EM 31 DE DEZEMBRO (em RS)

\begin{tabular}{l|c|c}
\multicolumn{1}{c|}{ CRÉDITOS } & $\mathbf{2 0 0 3}$ & $\mathbf{2 0 0 2}$ \\
\hline RECEITAS & & \\
\hline Receitas Operacionais de Prest. Serviços: & 342.523 & 687.124 \\
\hline Convênios de Saúde Públicos & 156.452 & 649.585 \\
\hline Convênios de Saúde Privados & 186.071 & 37.540 \\
\hline & & \\
\hline Deduções das Receitas & $(2.084)$ & $(6.799)$ \\
\hline Glosas de Faturamento & $(2.084)$ & $(6.799)$ \\
\hline & & \\
\hline Receitas Não Operacionais: & 404.131 & 301.399 \\
\hline Promoções, Eventos e Projetos & 205.302 & 154.178 \\
\hline Doações Diversas & 195.538 & 143.030 \\
\hline Receita c/ Utilização da Marca & - & 1.800 \\
\hline Reversão de Despesas & 3.291 & 2.391 \\
\hline
\end{tabular}


(continuação)

\begin{tabular}{|c|c|c|}
\hline CRÉDITOS & 2003 & 2002 \\
\hline Receitas Financeiras: & 13.011 & 7.435 \\
\hline Rendimentos de Aplicações & - & 1.065 \\
\hline Descontos Obtidos / Ressarc. Despesas & 13.011 & 6.370 \\
\hline Total dos Créditos & 757.581 & 989.159 \\
\hline DÉBITOS & 2003 & 2002 \\
\hline \multicolumn{3}{|l|}{ DESPESAS } \\
\hline Custos dos Serviços Prestados: & 374.975 & 622.380 \\
\hline Medicamentos & 149.450 & 279.359 \\
\hline Mão-de-Obra e Encargos & 111.590 & 200.977 \\
\hline Serviços de Assistência Médica & 47.161 & 77.907 \\
\hline Encargos de Depreciações & 20.326 & 26.536 \\
\hline Materiais Diversos / Outros Custos & 46.447 & 37.601 \\
\hline Despesas Administrativas: & 433.765 & 335.652 \\
\hline Aluguéis & - & 92.914 \\
\hline Pessoal, Terceiros e Encargos & 130.289 & 133.688 \\
\hline Conserv. E Reparação de Instalações & 11.934 & 9.327 \\
\hline Impressos e Materiais de Consumo & 27.337 & 43.273 \\
\hline Impostos e Taxas & 5.609 & - \\
\hline Anuidades/Assinaturas/Congressos & 8.070 & 9.715 \\
\hline Locações / Fretes e Carretos & 54.583 & 11.100 \\
\hline Força / Luz / Água e Esgoto & 11.253 & - \\
\hline Telefones & 15.854 & 14.941 \\
\hline Depreciação & 15.649 & - \\
\hline Despesas Viagens, Estadias e Refeições & 4.859 & 6.708 \\
\hline Perdas no Recebimento de Créditos & 141.609 & - \\
\hline Demais Despesas & 6.719 & 13.986 \\
\hline Despesas Não Operacionais: & 30.261 & 26.237 \\
\hline Despesas com Promoções e Eventos & 23.321 & 26.237 \\
\hline Despesas com Reforma & 6.940 & - \\
\hline Outras Despesas: & 41.378 & 60.046 \\
\hline Gratuidades (nota 5) & 28.846 & 50.713 \\
\hline Desp. Bancárias, Juros, Multas etc. & 12.532 & 9.333 \\
\hline Total das Despesas & 880.379 & 1.044 .315 \\
\hline DÉFICITS DOS EXERCÍCIOS & $(122.798)$ & (55.156) \\
\hline Total dos Débitos & 757.581 & 989.159 \\
\hline
\end{tabular}

